Aus dem Anatomischen Institut der Med. Fakultät, Univ. Okayama (Vorstand: Prof. M. SEKI).

\title{
Über das Eintreten des lipoidlöslichen Farbstoffes, Viktoriablau, in die Nasen- und Rachenschleimhaut der Maus.
}

\author{
類脂溶性の染料ビクトリア青の二十日鼠の鼻と咽頭の粘膜 \\ への進入に就いて。
}

\author{
Hideo TAKAHASI 高 橋 秀夫. \\ [Eingegangen am 31. Januar 1954.]
}

Der Verfasser (1954) hat in die Naris der Maus eine Lösung eines für vitale Färbung gebräuchlichen Säurefarbstoffes, Trypanblau, eingetröpfelt und die Art und Weise des Eindringens dieses lipoidunlöslichen, verhältnismäßig großmolekularen Farbstoffes in die Nasen- und Rachenschleimhaut beobachtet. Zur Ergänzung war noch ein Experiment mit einem lipoidlöslichen Farbstoff notwendig, da die Zellen und die interzellularen Substanzen lipoidreich sind. Unter den lipoidlöslichen Farbstoffen empfahl KOYAMA (1950) Viktoriablau $4 \mathrm{R}$ als der beste. Es wurde mit diesem Farbstoff folgende Untersuchung vorgenommen.

\section{Material und Methode.}

Eine 1\%ige Lösung von Viktoriablau (der Firma MERCK) in 90\%igoem Alkohol wurde mit physiologischer NaCl-Lösung 5,000- und 10000 fach verdünnt und in die Nasenöffnung der Maus eingetröpfelt. Die erstere Verdünnung diente für die Untersuchung des Rachens, die letztere aber für die der Nasenhöhle. Die Farblösung wurde dabei unter Benutzung einer Glaspipette mit einer gestumpften Spitze von Zeit zu Zeit eingetröpfelt, damit die Farbe durch die eigene Flimmerbewegung des Schleimhautepithels nach hinten befördert würde.

Die Eintröpfelung der Farblösung dauerte, wie bei der früheren Arbeit mit Trypanblau, 2, 5, 10, 20 und 60 Minuten. Nach 3, 5, 10, 40 und 120 Minuten tötete man die Tiere. Die Versuchstiere betrugen 4 für jedes Experiment und 40 im ganzen. Gleich nach schneller Entfernung von Haut, Gehirnschädel und Zähnen wurde der Oberkiefer mit der Nasenhöhle für 1-2 Stunden in eine 10\%ige Formalinlösung gebracht, darauf zerlegte man das Objekt ohne Wasserspülung in Gefrierschnitte von $15-20 \mu$. Dicke. Die Hälfte der Schnitte wurde sofort, die andere Hälfte wurde aber nach einer schwachen Nachfärbung mit Kernechtrot, 
auf einem Objektglas einige Minuten getrocknet. Die Präparate wurden nach Eintauchen in Xylol im Xylolbalsam eingeschlossen. Es ist rätlich dem Xylol eine 10\%tige Ml丷enge von Benzol zuzusetzen, weil das reine Xylol dem Rest von Wasser im Schnitte zu felnd ist. Um zu sehen, ob der Farbstoff zum Teil während der Fixierung in der Formalinlösung in tiefere Schichten des Gewebes diffundiert oder aber sich aus dem Gewebe auslöst, wusch man schnell das Gewebestück mit physiologischer NaCllösung und zerlegte es ohne Fixierung in Gefrierschnitte, und man verglich dies mit den obigen Schnitten. Es wurde ferner nach 40 Minuten nach 20minutigen Eintröpfeln ein Gewebestück sofort, ein anderes Gewebsstück aber nach 2tägiger Fixierung in 10\%iger Formalinlösung in Gefrierschnitte zerlegt, und diese beiden Schnitte wurden verglichen. Durch eine nähere Untersuchung wurde bestätigt, daß praktisch der wasserunlösliche Farbstoff Viktoriablau sich während der Fixierung nicht verschieben.

\section{Ergebnisse der Versuche.}

\section{A. Nasenhöhle.}

\section{Regio respiratoria.}

3 Minuten nach einem 2minutigen Eintröpfeln. Der Farbstoff Viktoriablau färbt die Oberfläche des Flimmerepithels und dringt zugleich in die interzellularen Räume der Epithelzellen ein, wobei er die Seitenfläche der Epithelzellen färbt. Die Farbe erreicht aber nicht das subepitheliale Gewebe. Die Farbe geht besonders schnell durch die Spalträume um die Becherzellen.

Unter dem Epithel der Regio respiratoria färbt sich dasjenige des unteren Abschnittes des Nasenseptums und der hinteren Nasenöffinung am frühesten.

5 Minuten nach einem 5minutigen Eintröpfeln. Der Farbstoff dringt durch die Zellen selbst und durch die interzellularen Räume in die Tiefe des Epithels ein und gelangt durch die Basalmembran hindurch zum subepithelialen Bindegewebe, das er schwach färbt (Abb. 1). Der Farbstoff färbt die Oberfläche der Becherzellen stark, geht aber nicht in ihr Inneres. Durch genauere Untersuchung wird festgestellt, daß die Basalmembran, selbst wenn der Kern der Flimmerzellen und der Leib der Basalzellen noch ungefärbt bleiben, schon ziemlich distinkt gefärbt wird.

10 Minuten nach einem 10minugiten Eintröpfeln. Das Flimmerepithel wird, wie in Abb. 2 gezeigt, diffus gefärbt, wobei aber die Flimmerhaare, die interzellularen Räume und die Basalmembran sich besonders stark färben. Das Innere der Becherzellen färbt sich hier auch nicht gut und sieht wie eine Höhle aus. Die unter das Epithel eingegangene Farbe färbt die Bindegewebsfasern und die Wand der Blutkapillaren. 


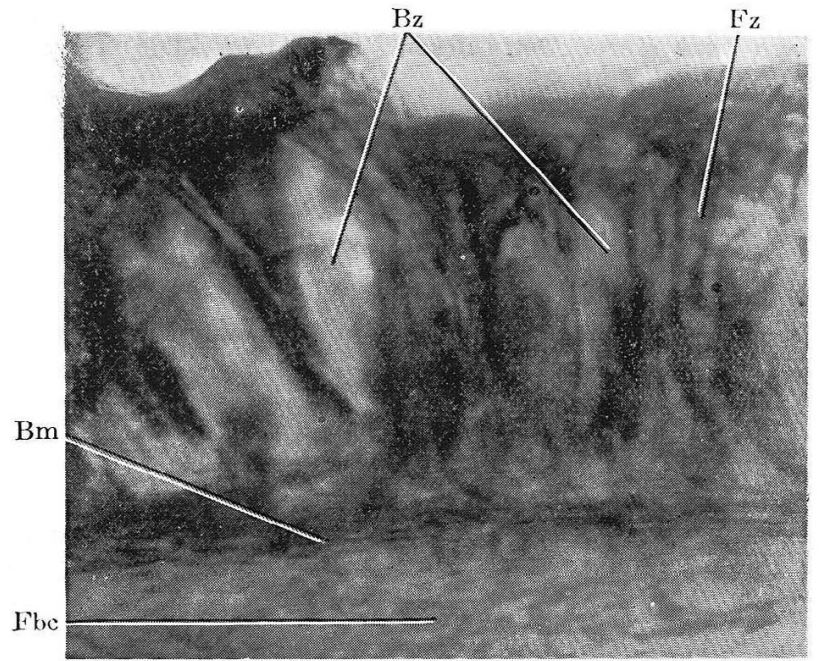

Abb. 1. Mehrreihiges Epithel der hinteren Nesenöfnung. 5 Minuten nach 5minutigen Eintröpfeln der Vilitoriablanlösung. Das Viktoriablan färbt die Zylinderepithelzellen. Die Basalmembran und das subepitheliale Gawebe sind auch gefärbt. Das Innere der Becherzellen bleibt ungefärbt. 1,000) . Erklärung der Abkürzungen in Abb. 1 bis 7: By Blutgefäß, Bm Basalmembran, Bz Becherzellen, Dr Drüse, D Drïenausfihrungsgang, Ep Epithel, $\mathbf{F}$ bc Fibrocyten, Hss Histiocyten, $\mathbf{F}_{\boldsymbol{z}}$ Zylinderepithel mit Fiimmerhaaren, Kd Kehldeckel, Kf kollagene Fasern, $\mathbf{M} \mathbf{z}$ Mastzellen, $\mathbf{n L}$ neutrophile Leukocyten, $\mathbf{R}$ Nasalte'1 des Rachenз, R. Oralteil des Rachens.

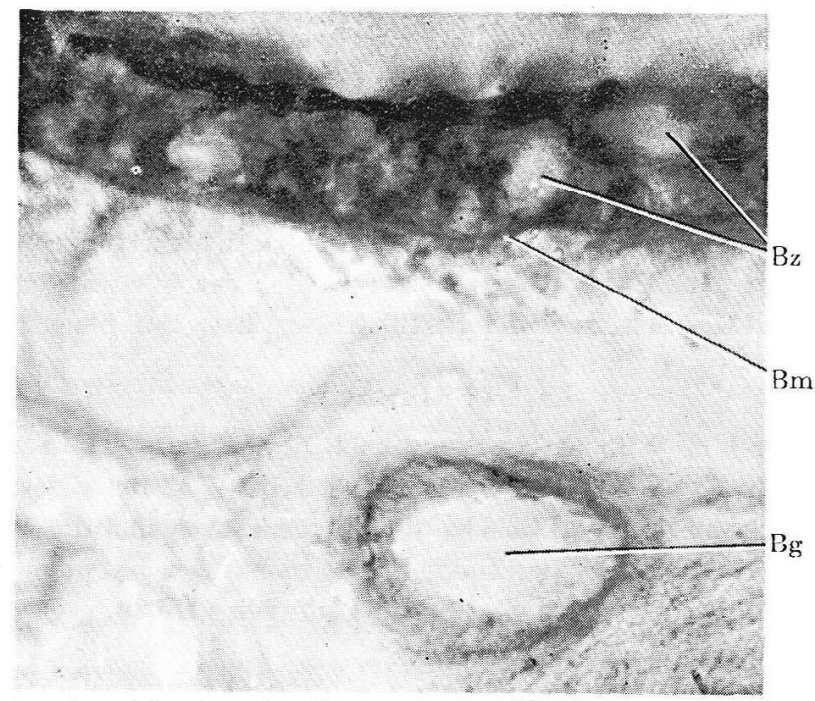

Abb. 2. Aus dem Mittelteil des Nasenseptums. 10 Minuten nach 10minutigen Eintröpfeln. Die Gefäßwand ist auch schwach gefärbt. Das Inmere der Becherzellen ist farbfrei. $400 \times$. 
40 Minuten nach einem 20minutigen Eintröpfeln. Die Flimmerzellen färben sich diffus so stark, daß man die einzelnen Zellen nicht mehr unterscheiden kann. Die Farbe geht viel mehr als in den früheren Zeiten in das subepitheliale Gewebe ein. Dabei färbt sich die Drüsenwand schwächer als die Gefäßwand. Man sieht stellenweise neutrophile, segmentkernige Zellen im Bindegewebe. Die Schleimhaut ist offenbar etwas entzündet. Gelegentlich werden Histiocyten mit aufgespeicherten, schwach blau gefärbten Granula und Mastzellen mit zahlreichen, viel stärker gefärbten spezifischen Körnchen getroffen.

Es wurden Schnitte aus zwei Gewebestücken, von denen das eine nicht fixiert und das andere in 10\%iger Formalinlösung 2 Tage fixiert worden war, vergleichend untersucht. In den Schnitten aus dem lange in der Fixierungsflüssigkeit aufbewahrten Gewebestück ist das Epithel durchschnittlich etwas stärker blau gefärbt. Aber die Weise des Eindringens der Farbe in das Gewebe und ihre Verbreitung in ihm ist die gleiche. Eine bedeutende Diffusion der Farbe während und nach der Fixierung wird also nicht wahrgenommen.

In den meisten Fällen tritt Viktoriablau in die Nebenhöhle der Nase ein. Nach 20minutigen Eintröpfeln erreicht die Farbe manchmal die Kapillarenwand unter dem Epithel, aber nur in geringem Grade. Das Epithel des Ductus nasolacrimalis und des JACOBSONschen Organs blieb immer ungefärbt.

\section{Regio olfactoria.}

Schon 3 Minuten nach 2minutigen Eintröpfeln färbt der Farbstoff den oberen Abschnitt der Riechzellen schwach, und 5 Minuten nach 5minutigen Eintröpfeln wird der Kern der Riechzellen gefärbt. Nach mehr als 10 Minuten dauerndem Eintröpfeln werden auch die Stützzellen des Epithels sowie verschiedene Gewebselemente unter dem Epithel schwach angefärbt. Der Kern der Riechzellen färbt sich dabei nur in geringem Grade besser als das Cytoplasma, dagegen wird der Kern bei Eintröpfeln, von Trypanblau, wie es SEKI (1940) gezeigt hat, tief blau tingiert.

\section{B. Rachen.}

Die durch die Flimmerbewegung nach hinten geflossene Farbe färbt, wie in Abb. 3 gezeigt, die laterale Wand des Nasalteils des Rachens, den Scheitelrand des Kehldeckels, den Zungenrücken und die Wände der auf den lateralen Seiten der Zunge liegenden Furchen besonders gut. An dem weichen Gaumen wird das Epithel schwach gefärbt.

\section{Nasaler Teil des Rachens.}

Erst 10 Minuten nach 10minutigem Eintröpfeln gelangt die Farbe zu der Rachenmündung der Ohrtrompete und zu der dorsalen Gegend derselben. Die Farbe dringt in das Epithel ein, wie bei der respiratori- 


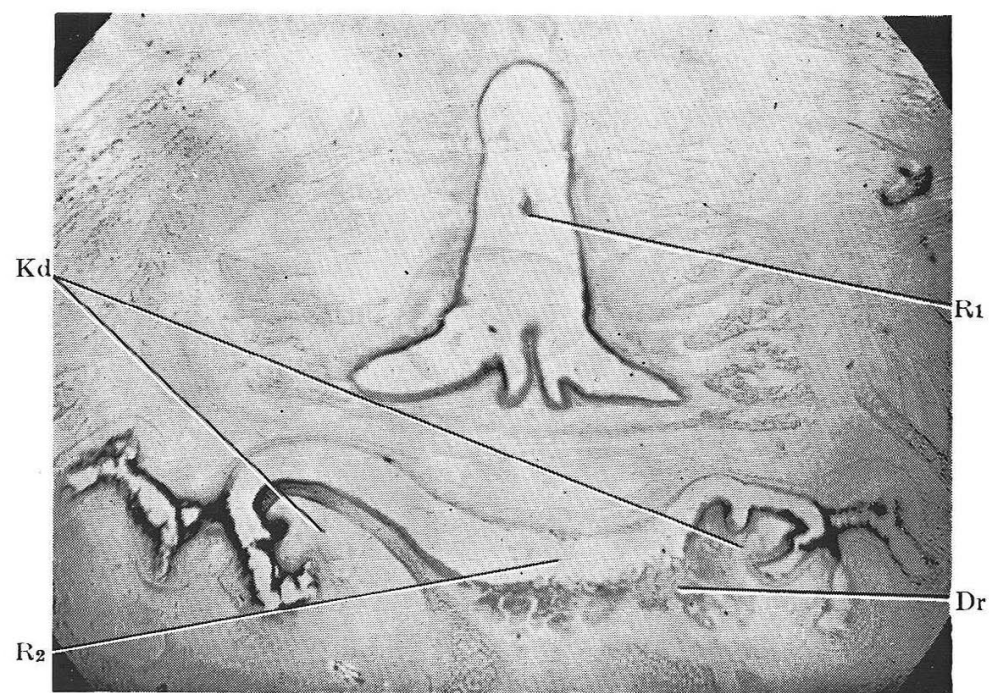

Abb. 3. Übersicht über den Rachen. Frontalschnitt. 40 Minuten nach 20minutigen Eintröpfeln. Der Farbstoff dringt leicht durch das Epithel an der lateralen Wand des Nasalteiles des Rachens und an der vorderen Fläche des Kehldeckels hindurch in das subepitheliale Gewebe ein. $22 \times$.

schen Regio der Nasenschleimhaut beobachtet wurde. Die Farbe tritt nur wenig in die Ohrtrompete. 40 Minuten nach 20 minutigem Eintröpfeln färbt die Farbe das Flimmerepithel diffus, erreicht über die Basalmembran hinaus das subepitheliale Gewebe und färbt die Bindegewebsfasern schwach (Abb. 4). Bei näherer Beobachtung findet man oft Mastzellen mit stark gefärbten Granula und Histiocyten mit schwächer gefärbten Speicherungen. Daneben werden auch neutrophile Leukozyten mit einem stark blau gefärbten Kern angetroflen, der oflenbar nach dem Tod der Zellen gefärbt ist.

40 Minuten nach 20minutigen Eintröpfeln dringt der Farbstoff durch das ventral von der Mündung der Ohrtrompete liegende, mehrreihige Epithel in das darunter gelegene Bindegewebe und färbt verschiedene Gewebselemente blaßblau.

\section{Oraler Teil des Rachens.}

Das in die Nasenhöhle eingetröpfelte Viktoriablau tritt nach 20 Minuten nirgends in das Epithel ein.

40 Minuten nach 20minutigen Eintröpfeln färbt sich aber das die ventrale Fläche des Kehldeckels bedeckende Zylinderepithel stark, zudem kolorieren sich auch viele Gewebselemente unter dem Epithel (Abb. 3). Das geschichtete Plattenepithel an anderen Orten wird nur in seiner oberflächlichen Schicht gefärbt. 


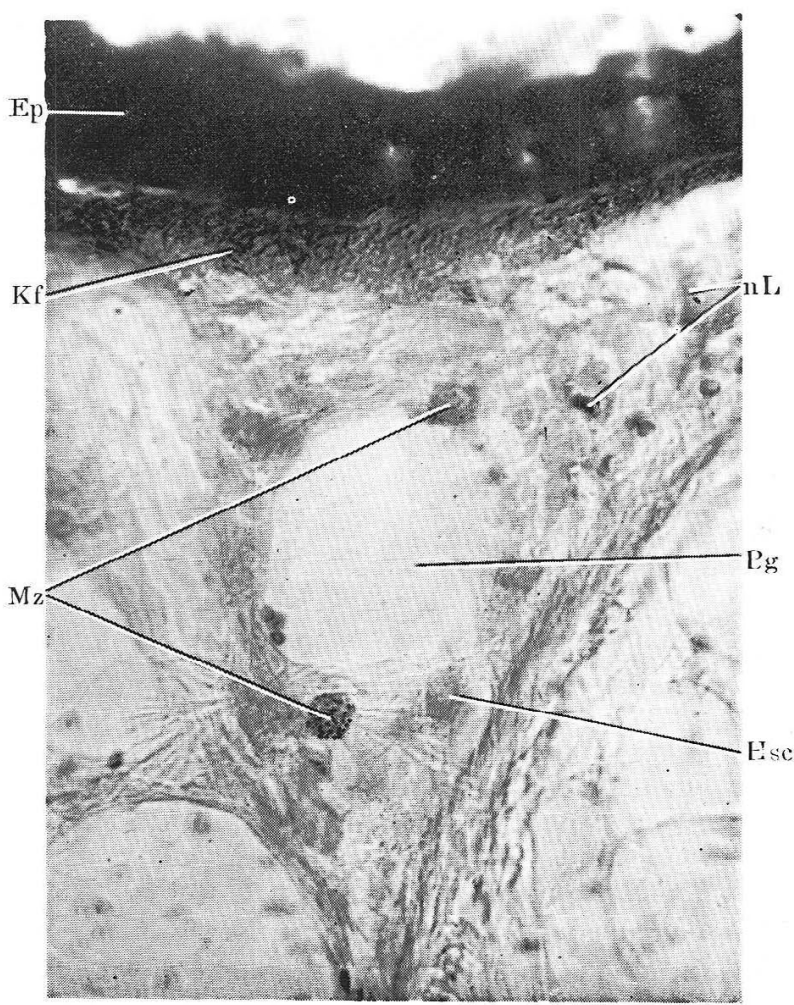

Abb. 4. Aus dem Nasalteil des Rachens gegenüber dem weichen G:umen. 40 Minuten nach 200minutigen Fintröpfeln. Der in das subenitheliale Gewebe eingewanderte Farbstoff färbt leicht die Bindegewebsfasern. Man sieht Mastzellen, Histiocyten und gestorbene nentrophile Leukocyten. $400 \times$.

2 Stunden nach lstïndigem Eintröpfeln färbt der Farbstoff nicht nur das geschichtete Plattenepithel auf der dorsalen Fläche des Kchldeckels und an der lateralen Wand des hinteren Teils des Rachens stark, sondern auch durch das Epithel hindurch viele Gewebselemente unter dem Epithel (Abb. 5 und 6). Aber am dicken geschichteten Plattenepithel des Zungenrückens und des weichen Gaumens tritt der Farbstoff nur bis zu den interzellularen Räumen seiner mittleren Schicht ein. Der Farbstoff geht nicht weit in die Ausführungsgänge der hier vorhandenen Drüsen und färbt, wie in Abb. 7 gezeigt, ihre Wand schwach. In dieser Zeit dringt der Farbstoff durch das geschichtete Plattenepithel am hinteren Teil des Bodens der Mundhöhle in das darunter gelegene Gewebe ein.

Nach einstündigem Eintröpfeln von Viktoriablau erscheinen neutrophile Leukocyten stellenweise im Bindegewebe, 2 Stunden nach dem 


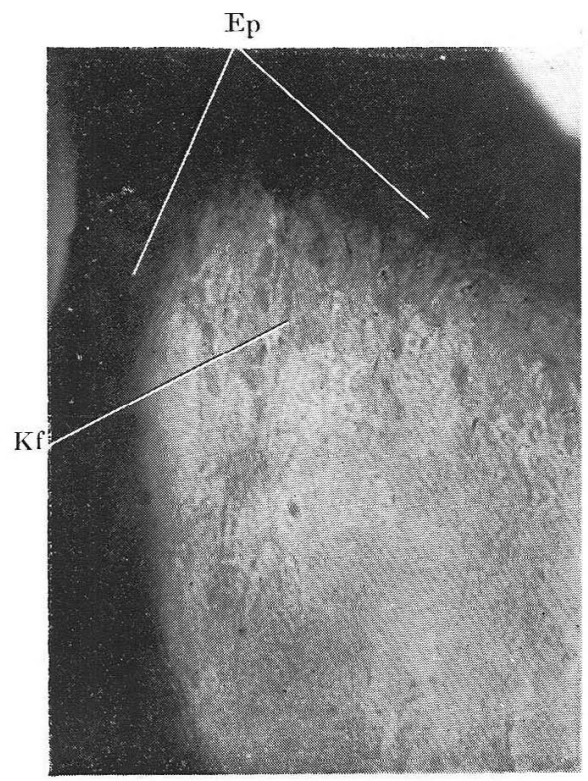

Abl. 5. Aus einem Ende des Kehldeckels. Frontalschnitt. 2 Stunden nach 1stündigem Eintröpfeln. Schwache Nachfärbung mit Kernechtrot. Der Farbstoff färbt das Epithel stark und geht in das subepitheliale Gewebe ïber. Die mit Viktoriablau gefärbten Gebilde im Bindegewebe sind dunkler und die mit Kernechtrot gefärbten sind schwaicher dargestellt. $510 \times$.

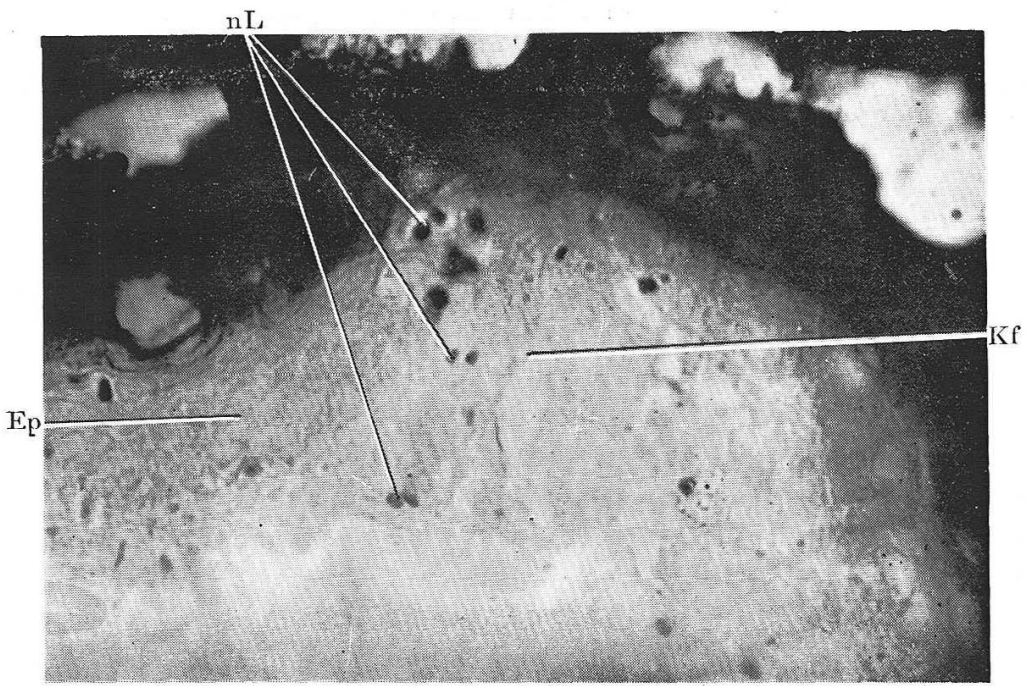

Abb. 6. Aus der dorsalen Wand des Oralteils des Rachens. 2 Stunden nach 1stiindigen Eintröpfeln. Das subepitheliale Gewebe ist hlaßblau mit Viktoriablau durchgetränkt. Der Kern von gestorbenen neutrophilen Leukocyten tingiert sich dunkel. $400 \times$. 


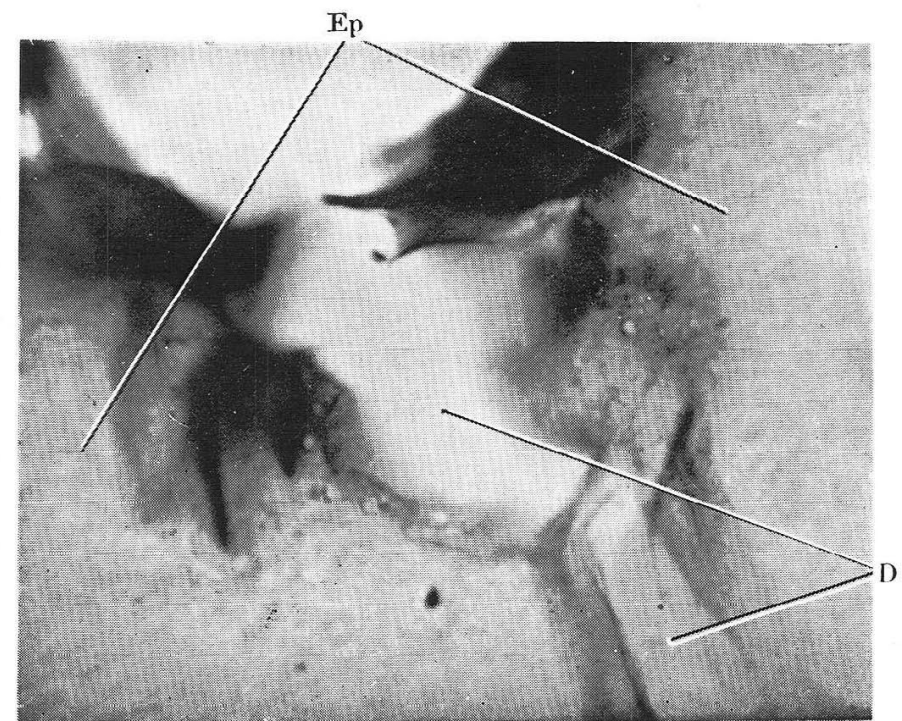

Abb. 7. Mündung eines Ausführungsgangs der Drüse auf dem Zungenrücken. 40 Minuten nach 20minutigem Eintröpfeln. Aus der Färbung des Fpithels des Ausführungsgangs ersieht man, daß die Farbe gegen den Sekretistrom nicht leicht in den Gang eingeht. $400 \times$.

lstündigen Eintröpfeln sieht man, wie in Abb. 6 gezeigt, hier ind da gestorbene neutrophile Zellen, deren Kern tief mit Viktoriablau gefärbt ist.

\section{Zusammenfassung.}

Ein in Wasser nicht löslicher, wohl aber lipoidlöslicher Farbstoff, Viktoriablau, wurde in Form einer wässeriger Lösung in die Naris der Maus eingetröpfelt, und dabci wurde die Art und Weise des Eintretens des Farbstoffes in die Nasen- und Rachenschleimhaut untersucht.

1. Das Viktoriablau färbt schnell den oberen Rand des Zylinderepithels mit Flimmerhaaren, erreicht durch die interzellularen Räume das Basalmembran und tritt dieses durch. Nach längeren Eintröpfeln der Viktoriablaulösung werden die ganzen Flimmerzellen diffus gefärbt, dabei bleibt der Inhalt der Becherzellen gewöhnlich kaum gefärbt.

2. In der Regio olfactoria der Nasenschleimhaut wird das Viktoriablau von den Riechzellen aufgenommen, färbt sie aber nicht so stark wie ein Säurefarbstoff, Trypanblau. Später färbt das Viktoriablau die St ïtzzellen.

3. Das geschichtete Epithel ist schwerer durchläßig als das Zylinderepithel. Aber nach längerem Eintröpfeln der Viktoriablaulösung bietet 
das Epithel an der dorsalen Fläche des Kehldeckels, der dorso-lateralen Wand des Oralteils des Rachens und dem Boden der Mundhöhle dem Farbstoff keinen Widerstand mehr. Das Epithel am Zungenrücken und weichen Gaumen läßt aber dabei die Farbe nicht durch.

4. Das lipoidlösliche Viktoriablau tritt im Vergleich zum lipoidunlöslichen Trypanblau mit einer etwa zweimal größeren Schnelligkeit durch das Zylinderepithel in das subepitheliale Gewebe ein. Es kann auch gegenüber dem Trypanblau leichter in das geschichtete Plattenepithel eingehen. Was bezüglich der relativen Leichtigkeit und Wege des Eintretens von Viktoriablau in die Naser- und Rachenschleimhaut beobachtet wurde, gilt wahrscheinlich auch von den ebenfalls lipoidlöslichen Alkaloiden, wie Cocain, und anderen verschiedenen lipoidlöslichen Arzneimitteln.

\section{內 容自抄。}

類脂質によく溶ける中等極性染料なるビクトリフ青の溶液を舅挖に滴入 すれば，先ず速かに二十日鼠の鼻腔の繊毛柱形上皮の頂縁を染め，類脂質 そ溶けない染料のトリパン青の約 2 倍の速さで上皮細胞の間隙に進入して, 細胞の表面を染めながら基底膜に達し，それを染めたのち上皮下に入る。 その間に染料は細胞体の内にも易く入り，䊼毛柱形上皮を普遍飞染める. これは類脂質に溶けない酸性染料のトリパン青が繊毛細胞の胞体を殆んど 染めず，主飞上皮細胞の間隙のみを通つて上皮下に進むのと違う。杯細胞 の粘液はビクトリテ青に染り難い.

嗅上皮では豀細胞の上部の笑超が早く染まり，次飞㤥が染まり，次いで 支柱細胞も淡染して上皮は普遍飞染まるが，トリパン青の場合のように嗅 細胞の上部と核が特に甚だ強く染まることはない。

咽頭口部の重層扁平上皮では他の柱形上皮の部に較べてやや染料の進入 が遅れるが，そのうち喉頭荅の背面，口腔底の上皮等は比較的染料を通し 易く，舌背や軟口荅の強い重層扁平上皮はそれを通さない。

ビクトリア青が舅腔と咽頭の粘膜へ進入する難易と通路について見たこ とは，やはり類脂溶性であるコカイン等のアルカロイドや他の種々の類脂 溶性の楽品にても同様であろう.

\section{Literatur.}

Koyama, Y. : Versuche der Färbung von Ölen und Fetten mit alkohollöslichen Farbstoffen. (Jap. m. dtsch. Zfass.) Atch. hist. jap. 1 (1950). Seki, M. : Vitalfärbung des Riechepithels der Maus mit Trypanblau. Z. Zell- 
forsch. 31 (1940) od. Arch. hist. jap. 3 (1952). - Takahasi, H.: Durchläßigkeit der Schleimhaut der Nase und des Rachens für lipoidunlösliches 'Trypanblau. Arch. hist. jap. 6 (1954). 